\title{
Thermal Decomposition Behavior of 3D Printing Filaments Made of Wood- filled Polylactic Acid (PLA)/Starch Blend
} Yufeng Sun ${ }^{1,2 *}$, Danbee Lee ${ }^{2}$, Yapeng Wang ${ }^{1}$, Suiliang Li ${ }^{1}$, Jilai Ying ${ }^{1}$, Xinping Liu ${ }^{1}$, Guangyin $\mathrm{Xu}^{1}$, Jaegyoung Gwon ${ }^{3}$, and Qinglin $\mathrm{Wu}^{2 *}$

${ }^{1}$ Collaborative Innovation Center of Biomass Energy, College of Mechanical and Electrical Engineering, Henan Agricultural University, Zhengzhou 450002, China; hansyf9397@henau.edu.cn(Y.S); 1749436461@qq.com(Y.W); 99149291@qq.com(S.L); bradyingliu@163.com(J.Y); 970401437@qq.com(X.L); xgy4175@126.com(G.X);

2 School of Renewable Natural Resources, Louisiana State University AgCenter, Baton Rouge, Louisiana 70803, United States; dlee112@lsu.edu (D.L); wuqing@lsu.edu(Q.W)

${ }^{3}$ Forest products department, National institute of Forest Science, 57 Hoegiro, Dongdaemun-gu, Seoul 02455

*Correspondence: hansyf9397@henau.edu.cn(Y.S); wuqing@lsu.edu(Q.W)

\begin{abstract}
Dynamic thermogravimetric (TG) analysis under nitrogen environment was used to understand the thermal decomposition process of 3D printing filaments made of wood-filled polylactic acid (PLA)/starch blend. The characteristic temperatures and apparent activation energy (AAE) of the filaments with various starch contents were calculated with well-known kinetic models by Friedman, Flynn-Wall-Ozawa, Coats-Redfern and Kissinger. With the increased starch content in the filament, the onset thermal decomposition temperatures of the filaments decreased gradually from 272.4 to $155.1^{\circ} \mathrm{C}$. The thermal degradation degree became smaller, and the transitional temperature interval became larger with increased starch proportion. The AAE values of the three types of filaments with different starch ratios varied between $97 \mathrm{~kJ} / \mathrm{mol}$ and $114 \mathrm{~kJ} / \mathrm{mol}$, depending on material composition and method of calculation. The improved understanding of thermal decomposition behavior of PLA-starchwood composites can help develop more biodegradable PLA/starch-based filaments for 3D printing.
\end{abstract}

Keywords: Wood-filled PLA; Thermal Decomposition; Starch, 3D printing

\section{Introduction}

3D printing is becoming popular with its rapid prototyping, low manufacturing cost, and short commercialization time [1-3]. Polylactic acid (PLA) and PLA-wood composites have been used to manufacture filaments for 3D printing with well-claimed 'green' properties. PLA, derived from agricultural resources, has a great potential to be an alternative material for petroleum-based polymers [4-7]. Wood fibers are renewable and biodegradable. However, PLA resin itself is not easily biodegraded with microbes at temperatures around $20-25^{\circ} \mathrm{C}$. Thus, PLA and PLA-wood composites are not exactly biodegradable materials according to the definition of the term 'biodegradability' [8,9].

Starch is a widely available and renewable raw material from the agricultural production system. It is commercially extracted from agricultural resources and has a rapid biodegradation rate as well as a small granule structure $[10,11]$. It has been shown that blending starch with PLA can improve the biodegradable property and reduce the production cost of the composites [12-16]. Generally, starch is blended into PLA composite with granular and gelatinized forms $[17,18]$. In addition, previous studies have shown that glycerol can be an effective compatibilizer to enhance the interfacial adhesion between hydrophobic PLA and hydrophilic starch [19-22].

The use of starch can affect thermal decomposition behavior of the PLA composite. In their study, Ohkita and Lee found that thermal stability decreased by blending corn starch into PLA [23]. This phenomenon was also observed by other researchers [24-28]. Zuo et al. investigated the effects of starch/PLA mixing ratios on the thermal properties of composites with glycerol as the plasticizer. The interdependence between starch and PLA in the thermal decomposition 
behavior and glass transition temperature, melting temperature and degree of crystallinity of PLA were shown to increase gradually as the starch/PLA ratio reduced [29]. A decomposition temperature about $459^{\circ} \mathrm{C}$ for the crosslinked blends of PLA/starch was found by Wang et al., which was not found in pure PLA, and it was illustrated that branched and crosslinked macromolecules were formed during reactive extrusion [12]. Eustathios et al. reported that some small polar molecules were generated, and they could break down polyester chains during decomposition of wood-flour and starch blended in the PLA [30].

Activation energy (AE) is often used to investigate the thermal decomposition process of fiber composite materials. Typically, AE values are calculated from well-known kinetics methods including Friedman, Flynn-Wall-Ozawa, Coats-Redfern, and Kissinger equations [3134]. Wang et al. investigated AE of decomposition of thermoplastic dry starch (DTPS)/PLA blends with maleic anhydride as a compatibilizer. It was suggested that AE values of starch decreased dramatically after the blending process [12]. Jie et al. found that the crystallization activation energy of neat PLA calculated from the Arrhenius method had a higher value than that of thermoplastic starch (TPS)/PLA composite [35]. AE values of starch in DTPS/PLA and TPS/PLA composite increased by added glycerol as a compatibilizer, because glycerol helped the improved dispersion and compatibility between starch and PLA [36]. Shubhashini et al. studied the correlation of activation energy with thermal degradation of the hemp-PLA composites, and they found that thermal stability was improved due to the higher activation energy value resulted from higher bond energy [37].

Starch/PLA and wood flour/PLA composites have been studied, but there have been few studies that have attempted to analyze the kinetics of thermal degradation of the wood filled PLA composite blended with starch. Therefore, the objective of this study was to understand thermal decomposition behavior of wood-filled PLA/starch composites targeted for 3D printing by using several kinetic models.

\section{Materials and Methods}

\subsection{Materials}

Wood-filled PLA filament (FS-003) with $20 \mathrm{wt} \%$ wood fiber and a small percentage of colorant was obtained from Bizard Tech (Dallas, TX, USA) having a diameter of $1.75 \mathrm{~mm}$ (Dimensional accuracy $+/-0.02 \mathrm{~mm}$ ). Corn starch (Earthborn Elements) was purchased from InPivota Corp. (American Fork, UT, USA). These two materials used as main materials for manufacturing composites. Glycerol used as a compatibilizer between wood-filled PLA and corn starch, and it was supplied by Carolina Biological Supply Co. (Burlington, NC, USA).

\subsection{Material Preparation}

Three types of materials were prepared for comparing the thermal decomposition behavior of each composite. Wood-filled PLA (PW) filament with about $20 \%$ wood was a commercial product as the control group. The other two filaments were manufactured with two different PW and TPS ratio in the laboratory. TPS was prepared by mixing $70 \mathrm{wt} \%$ corn starch and $30 \mathrm{wt} \%$ glycerol in a steel cup for $10 \mathrm{~min}$. The PW filament was cut into small pieces by the pelletizer (BT25, Bay Plastics Machinery, Bay City, MI, USA). Then, TPS and small PW filament pieces were blended together with two PW/TPS ratios of 90/10 and 80/20 in the highspeed mixer (CIT-FW-200, Columbia International, Irmo, SC, USA) for 5min. Finally, the mixture was fed into the filament extruder (EX2, Filabot, Barre, VT, USA) to produce 3D printing filament with a diameter of $1.75 \mathrm{~mm}$. The temperature of the extruder was set at $175^{\circ} \mathrm{C}$. The obtained filaments were cut into small pieces and the material was extruded again to enhance the mixing of the two materials. These final filaments were named PW9S1 and PW8S2, respectively, according to their PW and TPS ratios. 


\subsection{Characterization}

The microstructure of three different filaments was examined by Scanning Electron Microscopy (SEM). Prior to SEM observation, all filaments were dipped in liquid nitrogen and impact-broken. The brittlely fractured surfaces were coated with Pt of about $4 \mathrm{~nm}$ thickness by using a sputter coater. The morphology observations were conducted with a Quanta ${ }^{\mathrm{TM}} 3 \mathrm{D}$ DualBeam $^{\mathrm{TM}}$ FEG FIB-SEM (FEI Company, Eindhoven, the Netherlands) using a $5 \mathrm{kV}$ acceleration voltage. To analyze the chemical structures of filaments, the infrared (IR) spectra were attained using Fourier Transform Infrared (FTIR) Spectrometer (ALPHA, Bruker Corp, Billerica, MA, USA) with ATR accessory. The scan range was from 4000 to $400 \mathrm{~cm}^{-1}$ with 64 total scans and $4 \mathrm{~cm}^{-1}$ spectral resolution. The FTIR samples were first ground into powders prior to being put into the FTIR spectrometer. Thermal decomposition properties of the filaments were obtained by using a Q50 thermogravimetric analyzer (TA Instruments Inc., New Castle, DE, USA) at four different heating rates of $5,10,15$, and $20^{\circ} \mathrm{C} / \mathrm{min}$ in the $30-600^{\circ} \mathrm{C}$ temperature range under nitrogen. The flow rate of nitrogen was $40 \mathrm{ml} / \mathrm{min}$. Each tested sample weight was about $20 \mathrm{mg}$.

\subsection{Thermal decomposition kinetics}

The fundamental equations to assess thermal degradation kinetics based on the thermogravimetric (TG) data are described as follows [32].

$\mathrm{d} \alpha / \mathrm{dt}=\mathrm{Aexp}(-\mathrm{E} / \mathrm{RT}) \mathrm{f}(\alpha)$

and when the heating rate, $\beta=\mathrm{dT} / \mathrm{dt}$, is introduced into equation (1), the equation (2) becomes,

$$
\mathrm{d} \alpha / \mathrm{dT}=(\mathrm{A} / \beta) \exp (-\mathrm{E} / \mathrm{RT}) \mathrm{f}(\alpha)
$$

where $\alpha$ is the weight conversion degree, $\mathrm{d} \alpha / \mathrm{dt}$ is the weight conversion rate, $\mathrm{A}$ is the preexponential factor, $\mathrm{R}$ is the general gas constant $(8.314 \mathrm{~J} / \mathrm{K} \cdot \mathrm{mol}), \mathrm{T}$ is the absolute temperature, $\mathrm{E}$ is the apparent activation energy, $\mathrm{f}(\alpha)$ is the reaction model, which depends on the actual reaction mechanism, such as the methods listed in Table 1. The methods of Friedman (FD), Flynn-Wall-Ozawa (FWO), Kissinger (KS), and Coats-Redfern (CR) are commonly used to calculate the apparent activation energy (AAE).

Table 1. Thermal kinetic methods commonly used to calculate apparent activation energy of various materials

\begin{tabular}{lll}
\hline Methods & Equations & Plots \\
\hline $\begin{array}{l}\text { Friedman (FD) } \\
\text { Flynn-Wall-Ozawa }\end{array}$ & $\ln (\mathrm{d} \alpha / \mathrm{dt})=\ln [\mathrm{Af}(\alpha)]-\mathrm{E} / \mathrm{RT}$ & $\ln \mathrm{d} \alpha / \mathrm{dt}$ against $1 / \mathrm{T}$ \\
$\begin{array}{l}\text { (FWO) } \\
\text { Kissinger (KS) }\end{array}$ & $\log \beta=\log (\mathrm{AE} / \operatorname{Rg}(\alpha))-2.315-0.4567 \mathrm{E} / \mathrm{RT}$ & $\log \beta$ against $1 / \mathrm{T}$ \\
Coats-Redfern (CR) & $\ln \left[\beta /\left(\mathrm{T}_{\mathrm{p}}^{2}(1-2 \mathrm{RT} / \mathrm{E})\right)\right]=\ln \left[\mathrm{AR}[\mathrm{ER})+\left(1 / \mathrm{T}_{\mathrm{p}}\right)(-\mathrm{E} / \mathrm{R})\right.$ & $\ln \left(\beta / \mathrm{T}_{\mathrm{p}}^{2}\right)$ against $1 / \mathrm{T}_{\mathrm{p}}$ \\
&
\end{tabular}

\section{Results and Discussion}

\subsection{Basic filament properties}

Figure $1(a, b$, and $c)$ shows morphology of the original PW filament at the three different magnifications levels. The fracture surface shows circularly-shaped wood filler and apparent microvoids, partially due to pull-out of the filler particles during sample fracturing process [38]. There seems to be little bonding between the wood filler and PLA matrix within the commercial PW filament with 20\% wood fill (Figure 1c). 
Figure 1 (d, e, and f) shows morphology of the PWS2 filament at the three different magnifications levels. Both wood filler (20\% fill rate) and TSP (20\% fill rate based on original PW filament weight) particles are present in the system (Figure $1 \mathrm{e}$ and $\mathrm{f}$ ). Many microvoids still existed in the PW8S2 filament. The presence of microvoids could be water-evaporation related during extrusion - due to incomplete drying of the PLA resin or moisture induced from wood and starch. The presence of micro-voids could weaken the strength property of the filament and the use of compatibilizers can help improve bonding between wood filer and PLA matrix [10].
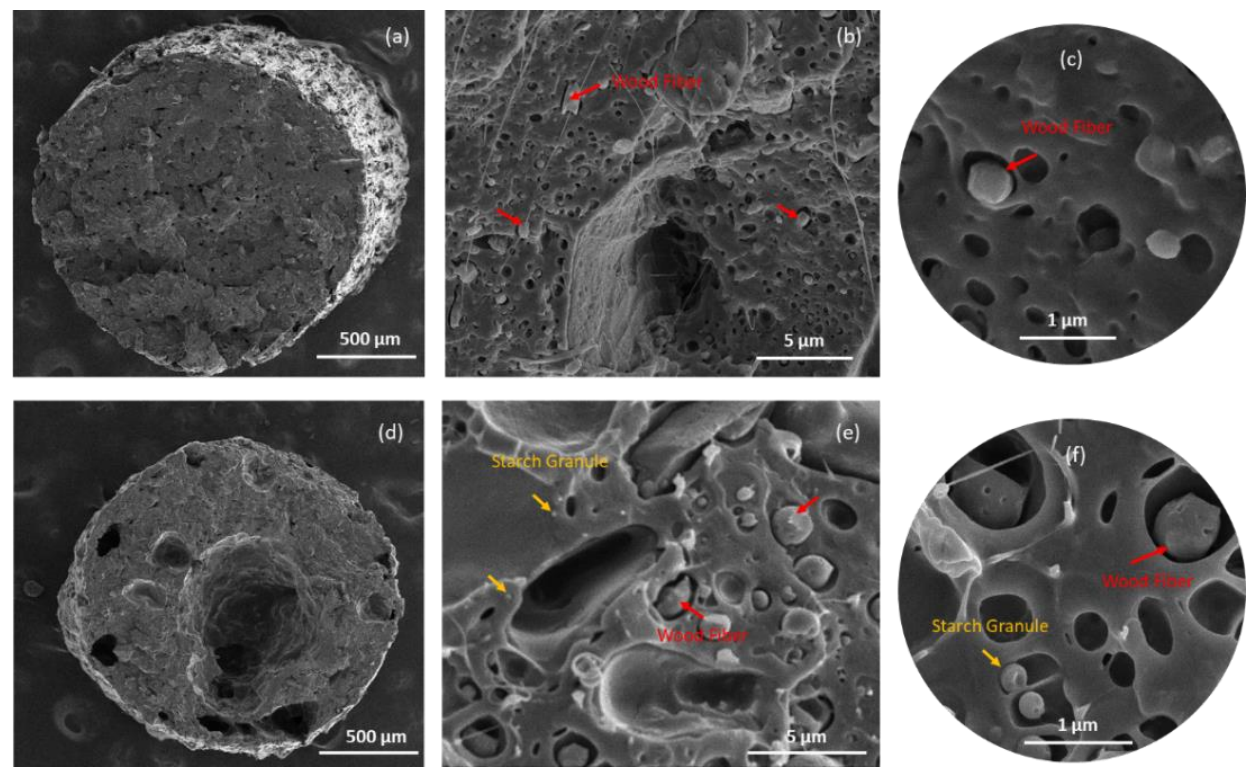

Figure 1. SEM images of composite filaments at different magnification levels. PW filament: $a, b$, and c, and PWS2 filament: $d, e$, and $f$.

Figure 2 shows a comparison of the FTIR spectra curves of the three filament samples. The absorption band at $1749 \mathrm{~cm}^{-1}$ of PW filament represented to the stretching vibration of carbonyl group $\mathrm{C}=\mathrm{O}[16,39]$. A weak peak at $1450 \mathrm{~cm}^{-1}$ was caused by the deformation vibration of methyl group $-\mathrm{CH}_{3}$, and the weak peak at $1364 \mathrm{~cm}^{-1}$ correspond to the symmetric and asymmetric deformation of C-H bond [40]. The peaks at $1194 \mathrm{~cm}^{-1}$ and $1071 \mathrm{~cm}^{-1}$ attributed to stretching vibration of $\mathrm{C}-\mathrm{O}$ bond [41]. The $873 \mathrm{~cm}^{-1}$ peak was ascribed to the stretching vibration of terminal methylene group $-\mathrm{CH}_{2}-$ [42].

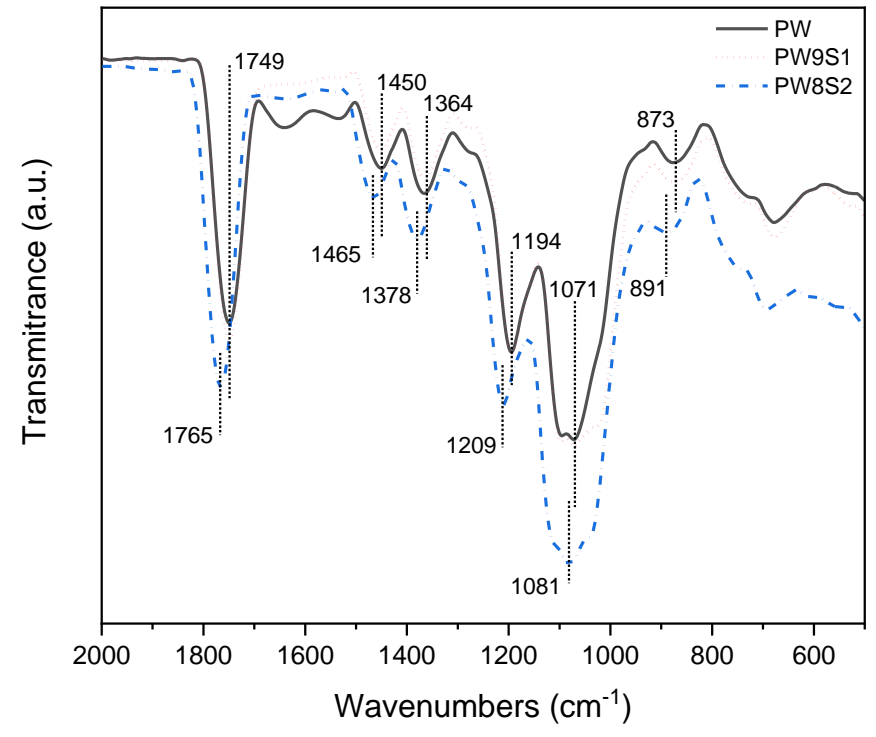


Figure 2. FTIR curves of the PW, PW9S1, and PW8S2 filament samples.

The FTIR spectra of PW9S1 shows the same absorption peaks with PW filament, while the wavenumbers of PW8S2 shifted to higher values $(1765>1749,1456>1450,1378>1364$, $1209>1194,1081>1071,891>873)$. In the meantime, the intensity of the $\mathrm{C}=\mathrm{O}\left(1765 \mathrm{~cm}^{-1}\right)$ and C-O $\left(1081 \mathrm{~cm}^{-1}\right)$ stretching bands of PW8S2 increased sharply compared with the other two filaments. This result suggested that adding $20 \mathrm{wt} \%$ starch led to a more detectable change of the surface structure in the PW8S2 filament.

\subsection{Thermal degradation characteristics}

\subsubsection{TGA data}

Figure 3 shows the TG and derivative thermogravimetric (DTG) curves of the filaments. PW9S1 was used as an example in Figure 3 (a) and (b). It can be observed that the TG and DTG curves were shifted towards right and the peaks of DTG curves became weaker with the increase in heating rate. The thermal decomposition progress of the filaments was determined by kinetic parameters, which were obtained from the TG, DTG, and $\mathrm{D}^{2} \mathrm{TG}$ curves of filaments. Figure 4 shows how to calculate decomposition parameters of filaments using PW9S1 at the $5^{\circ} \mathrm{C} / \mathrm{min}$ heating rate as an example. The onset temperature, $\mathrm{T}_{\mathrm{o}}$, was calculated from the extrapolation of the first derivative curve corresponded with the first local maximum peak in the second temperature derivative curve and down to the zero level of the DTG axis [32]. The first peak of the DTG curve indicated the peak temperature, $T_{p}$, in which the maximum decomposition rate happened. The shift temperature, $\mathrm{T}_{\mathrm{s}}$, was obtained by the extrapolation of the first derivative curve with the first local minimum peak in the second derivative curve and going to the zero level of the DTG axis [32,33].

Typical TGA parameters of the three filaments at four heating rates are presented in Table 2. $W_{o}, W_{p}$, and $W_{s}$ were the weight loss proportions in correspondence with $T_{o}, T_{p}$, and $T_{s}$, respectively. The differences of weight loss, $\mathrm{W}_{\mathrm{s}}-\mathrm{W}_{0}$, and that of the temperature, $\mathrm{T}_{\mathrm{s}}-\mathrm{T}_{0}$ of the three samples, were about $81.8 \%$ and $80.4^{\circ} \mathrm{C}, 81.1 \%$ and $125.7^{\circ} \mathrm{C}, 79.7 \%$ and $176.1^{\circ} \mathrm{C}$ for $\mathrm{PW}$, PW9S1, and PW8S2 filaments, respectively. The data suggested that the thermal degradation degree became smaller, and the temperature interval became longer with increased starch ratio in the filaments.

As shown in Table 2, the $T_{0}$ values increased with increased heating rate from $5^{\circ} \mathrm{C} / \mathrm{min}$ to $20^{\circ} \mathrm{C} / \mathrm{min}$ for all of three types of filaments. A trend of increase in the $T_{p}$, in which the maximum decomposition rate occurred, was also observed with an increased heating rate. The $\mathrm{T}_{\mathrm{s}}$ showed the same tendency to change as $T_{o}$ and $T_{p}$. Meanwhile, the mean value of the final char residue weight of PW9S1 was about $6.75 \%$. The residue value of PW filament was shown to have a similar tendency to PW9S1, but PW8S2 had slightly more residue than that of PW and PW9S1. This result suggested that starch could be effective for forming carbonized residue after thermal decomposition process at temperatures above $500^{\circ} \mathrm{C}$ [13]. Figure 3 (c), (d), and Table 2 show that the TG and DTG curves were shifted when the starch ratio was increased. The To values of filaments gradually decreased with the increased starch ratio $\left(302.6>256.5>205.7^{\circ} \mathrm{C}\right)$, while the smaller changes occurred to $\mathrm{T}_{\mathrm{p}}$ and $\mathrm{T}_{\mathrm{s}}$. The data suggested that the high starch/PLA ratio of the composites contributed to an early thermal decomposition of the filaments. The thermal stability of starch was slightly lower than that of PLA [43]. 

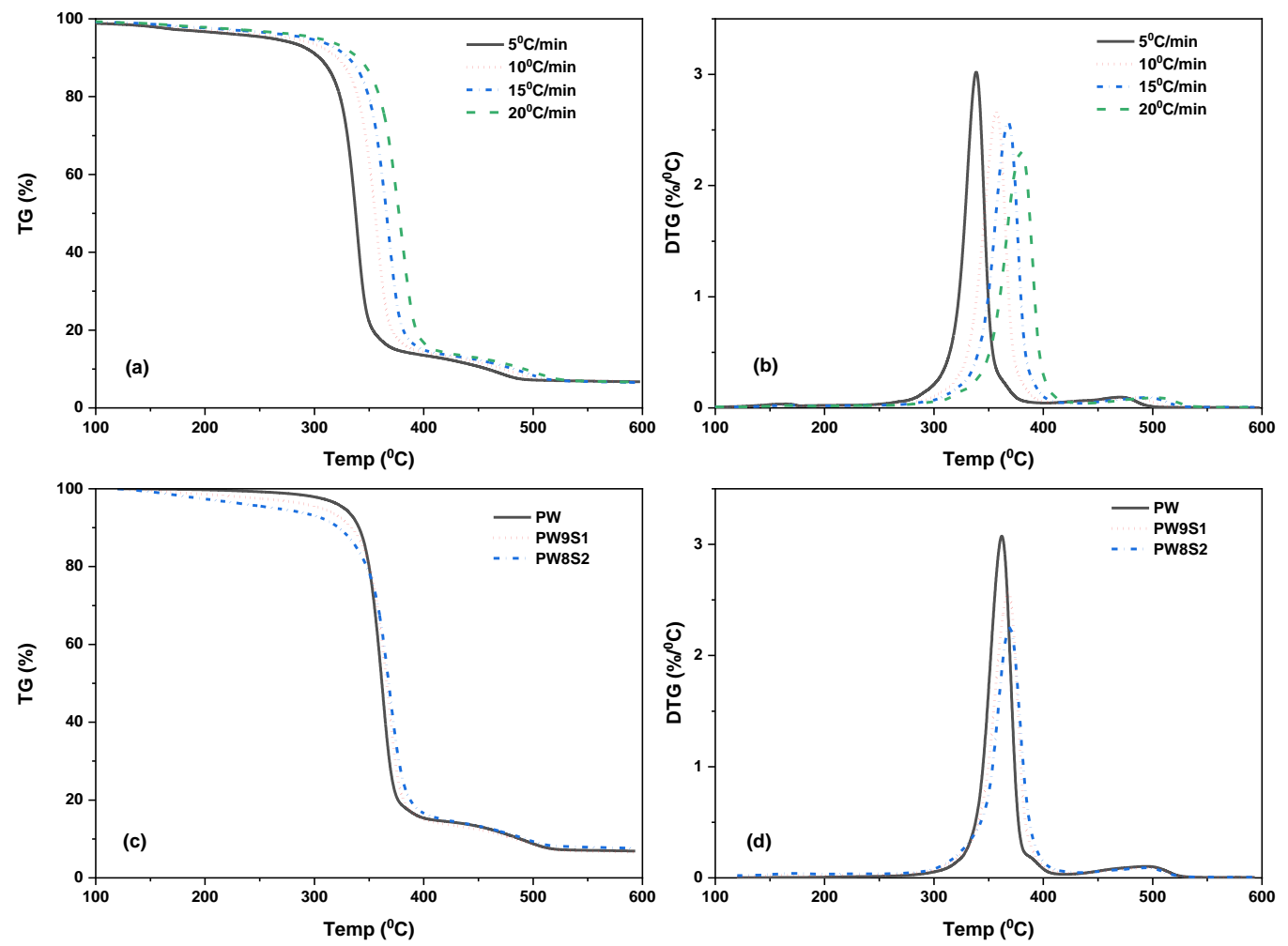

Figure 3. TG and DTG plots for the filaments: (a) TG plot for PW9S1 with different heating rates, (b) DTG plot for PW9S1 with different heating rates, (c) TG plot of PW, PW9S1, and PW8S2 at $15^{\circ} \mathrm{C} / \mathrm{min}$ heating rate, (d) DTG plot of PW, PW9S1, and PW8S2 at the $15{ }^{\circ} \mathrm{C} / \mathrm{min}$ heating rate.

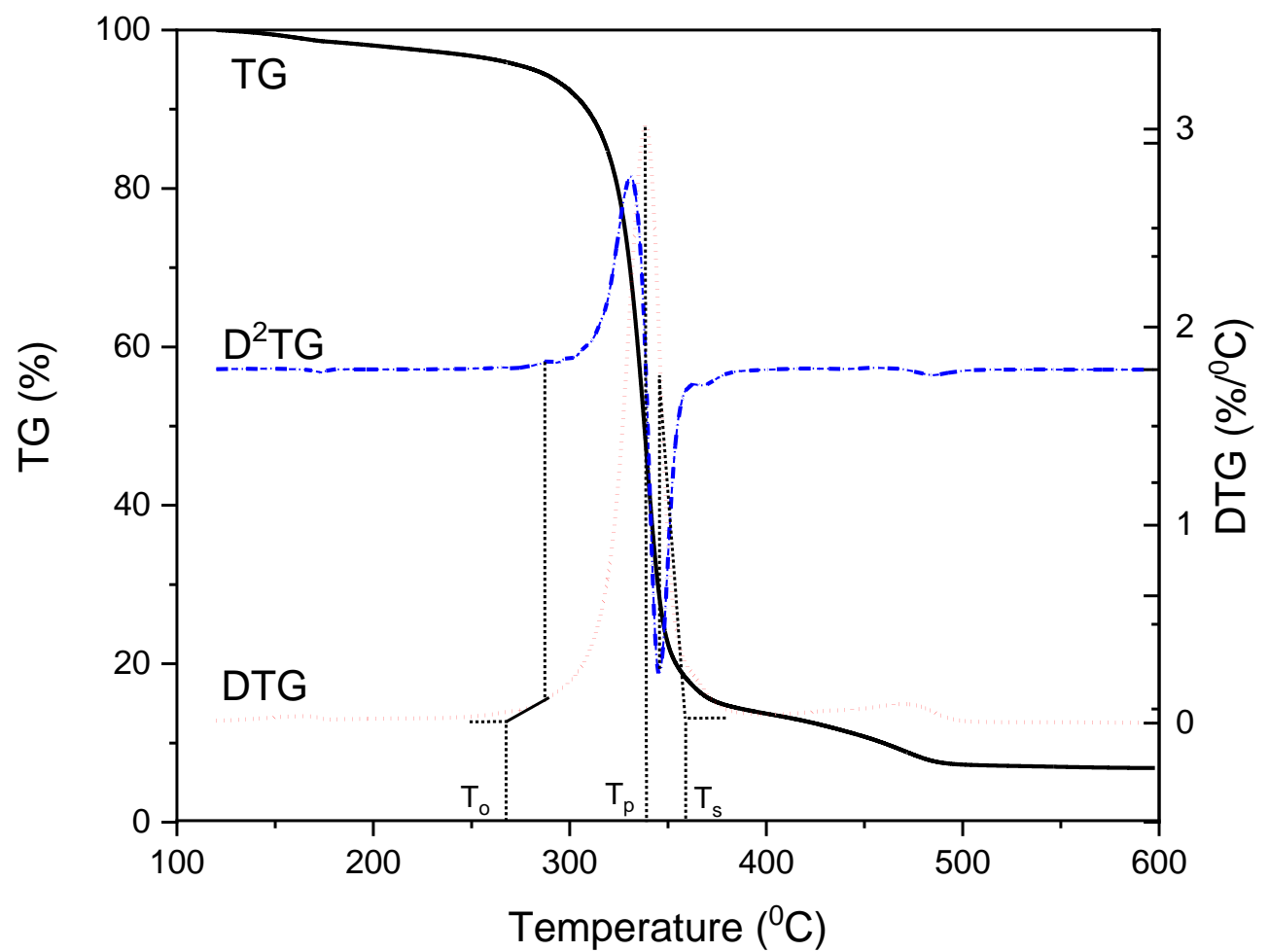

Figure 4. Calculation method of decomposition parameters of PW9S1 at the $5^{\circ} \mathrm{C} / \mathrm{min}$ heating rate. 
Table 2. Thermal decomposition kinetic parameters of the filaments.

\begin{tabular}{llccccccccc}
\hline Sample & $\begin{array}{c}\text { HR } \\
\left({ }^{\circ} \mathbf{C} / \mathbf{m i n}\right)\end{array}$ & $\begin{array}{c}\mathbf{T}_{\mathbf{0}} \\
\left({ }^{\circ} \mathbf{C}\right)\end{array}$ & $\begin{array}{c}\mathbf{W}_{\mathbf{0}} \\
\mathbf{( \% )}\end{array}$ & $\begin{array}{c}\mathbf{T}_{\mathbf{p}} \\
\left({ }^{\circ} \mathbf{C}\right)\end{array}$ & $\begin{array}{c}\mathbf{W}_{\mathbf{p}} \\
\mathbf{( \% )}\end{array}$ & $\begin{array}{c}\mathbf{T}_{\mathbf{s}} \\
\left({ }^{\circ} \mathbf{C}\right)\end{array}$ & $\begin{array}{c}\mathbf{W}_{\mathbf{s}} \\
(\mathbf{\%})\end{array}$ & $\begin{array}{c}\mathbf{R E S} \\
(\mathbf{\%})\end{array}$ & $\begin{array}{c}\mathbf{T}_{\mathbf{s}}-\mathbf{T}_{\mathbf{0}} \\
\left({ }^{\circ} \mathbf{C}\right)\end{array}$ & $\begin{array}{c}\mathbf{W}_{\mathbf{s}}-\mathbf{W}_{\mathbf{0}} \\
(\mathbf{\%})\end{array}$ \\
\hline \multirow{3}{*}{ PW } & 5 & 277.1 & 2.3 & 339.9 & 55.9 & 355.9 & 81.1 & 6.5 & 78.8 & 78.8 \\
& 10 & 297.4 & 2.4 & 359.5 & 57.8 & 372.8 & 81.5 & 6.6 & 75.4 & 79.1 \\
& 15 & 302.6 & 2.2 & 362.1 & 50.9 & 378.2 & 80.7 & 6.9 & 75.6 & 78.5 \\
& 20 & 306.9 & 2.0 & 382.5 & 56.8 & 398.7 & 92.7 & 6.9 & 91.8 & 90.7 \\
& PW9S1 & & & & & & & 6.7 & 80.4 & 81.8 \\
& 5 & 235.4 & 2.8 & 338.6 & 52.1 & 353.7 & 79.8 & 6.8 & 118.3 & 77.0 \\
& 10 & 253.1 & 2.9 & 357.1 & 54.0 & 373.5 & 81.0 & 6.9 & 120.4 & 78.1 \\
& 15 & 256.5 & 2.6 & 368.0 & 55.0 & 384.8 & 81.6 & 6.6 & 128.3 & 79.0 \\
& 20 & 263.0 & 2.6 & 379.9 & 55.6 & 398.7 & 92.8 & 6.7 & 135.7 & 90.2 \\
& PW8S2 & & & & & & & 6.8 & 125.7 & 81.1 \\
& 5 & 178.6 & 2.5 & 335.7 & 50.8 & 350.7 & 79.2 & 7.4 & 172.1 & 76.7 \\
& 10 & 187.1 & 2.4 & 355.0 & 52.5 & 371.8 & 79.0 & 7.3 & 184.7 & 76.6 \\
& 15 & 205.7 & 2.8 & 369.2 & 52.7 & 389.1 & 80.7 & 7.6 & 183.4 & 77.9 \\
& 20 & 234.2 & 3.6 & 377.4 & 53.2 & 398.2 & 91.1 & 7.5 & 164.0 & 87.5 \\
& mean & & & & & & & 7.5 & 176.1 & 79.7 \\
\hline
\end{tabular}

Figure 5 shows the method to calculate thermal decomposition kinetic characteristic parameters- $\operatorname{To}_{\beta}, \operatorname{Tp}_{\beta}$, and $\operatorname{Ts}_{\beta}$. These were obtained from the extrapolation of the temperature plots to the $\beta=0$ position. This method was used to eliminate the impact of the heating rates on the above characteristic temperatures. The typical values of the above the temperatures and the related weight losses are listed in Table 3.

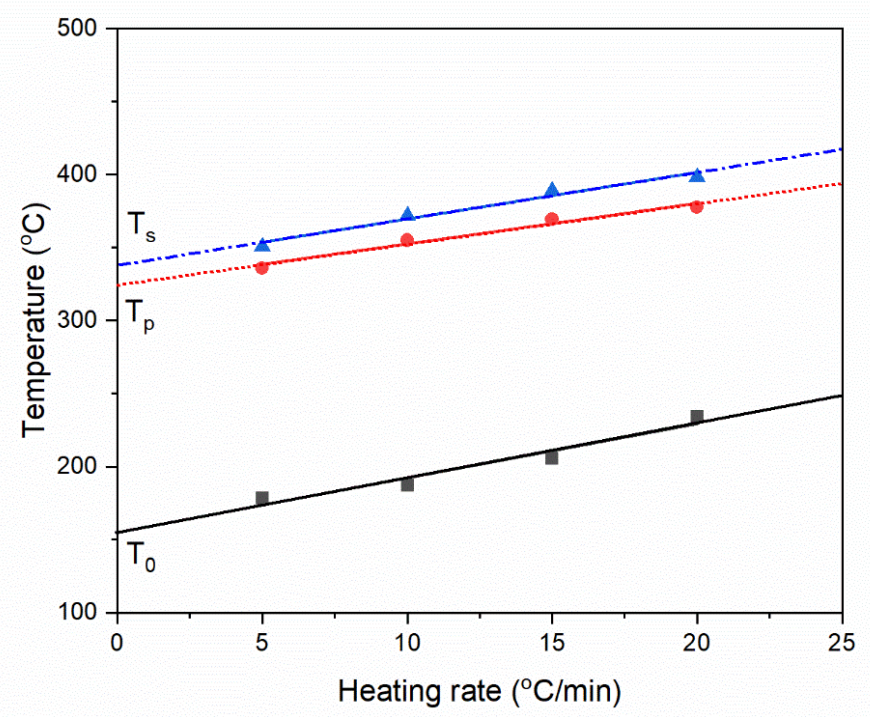

Figure 5. Calculation method of thermal decomposition kinetic characteristic parameters (To $\beta, \operatorname{Tp} \beta$, and $\mathrm{Ts}_{\beta}$ ) using the PW8S2 filament as an example.

Table 3. Decomposition parameters of filaments after a linear extrapolation to the $\beta=0$ position.

\begin{tabular}{|c|c|c|c|c|c|c|}
\hline \multirow[b]{2}{*}{ Sample } & \multicolumn{3}{|c|}{ Temperature } & \multicolumn{2}{|c|}{ Weight loss } & \multirow[b]{2}{*}{$\begin{array}{l}\text { Residue } \\
\text { (\%) }\end{array}$} \\
\hline & $\begin{array}{l}\mathrm{T}_{0 \beta} \rightarrow 0 \\
\left({ }^{\circ} \mathrm{C}\right)\end{array}$ & $\begin{array}{l}\mathrm{T}_{\mathrm{p} \beta} \rightarrow 0 \\
\left({ }^{\circ} \mathrm{C}\right)\end{array}$ & $\begin{array}{l}\mathrm{T}_{\mathrm{s} \beta} \rightarrow 0 \\
\left({ }^{\circ} \mathrm{C}\right)\end{array}$ & $\begin{array}{l}\text { WL } 0 \beta \rightarrow 0 \\
(\%)\end{array}$ & $\begin{array}{l}\text { WL } L_{s \beta} \rightarrow 0 \\
(\%)\end{array}$ & \\
\hline PW & 272.4 & 328.4 & 343.0 & $2.5(0.5)$ & $75.5(0.4)$ & 6.4 \\
\hline PW9S1 & 230.5 & 327.2 & 341.1 & $3.0(0.4)$ & $73.9(0.6)$ & 6.9 \\
\hline PW8S2 & 155.1 & 324.5 & 337.5 & $1.9(0.7)$ & $73.2(0.5)$ & 7.3 \\
\hline
\end{tabular}




\subsubsection{Determination of apparent activation energy}

Typical kinetic plots of Friedman (FD), Flynn-Wall-Ozawa (FWO), and Coats-Redfern (CR) methods show a primary decomposition trend of apparent activation energy (AAE) of PW, PW9S1, and PW8S2 filaments. The nearly parallel lines were obtained for PW sample in the conversion rate of 0.1-0.4 with the FD method - Figure 6 (a), which indicates similar AAE values at these positions. The lines became unparalleled at the conversion rate of 0.5 , which indicated that the thermal reaction mechanism might be changed from this stage [32]. In the FWO and CR methods (Figure 6b, 6c), the plots became paralleled upto a higher conversion rate $(\alpha=0.9)$, indicating that there was no thermal reaction mechanism change within the conversion rates. The plots with the FD, FWO, and CR methods for the PW9S1 filament were similar to these of PW. It implied a similar thermal decomposition mechanism. For the PW8S2 sample, the plot of FD method was different from the other two samples, and the plot was still parallel in the conversion rate of 0.5 . The plots of FWO and CR methods were similar to these of the PW9S1 and PW samples.
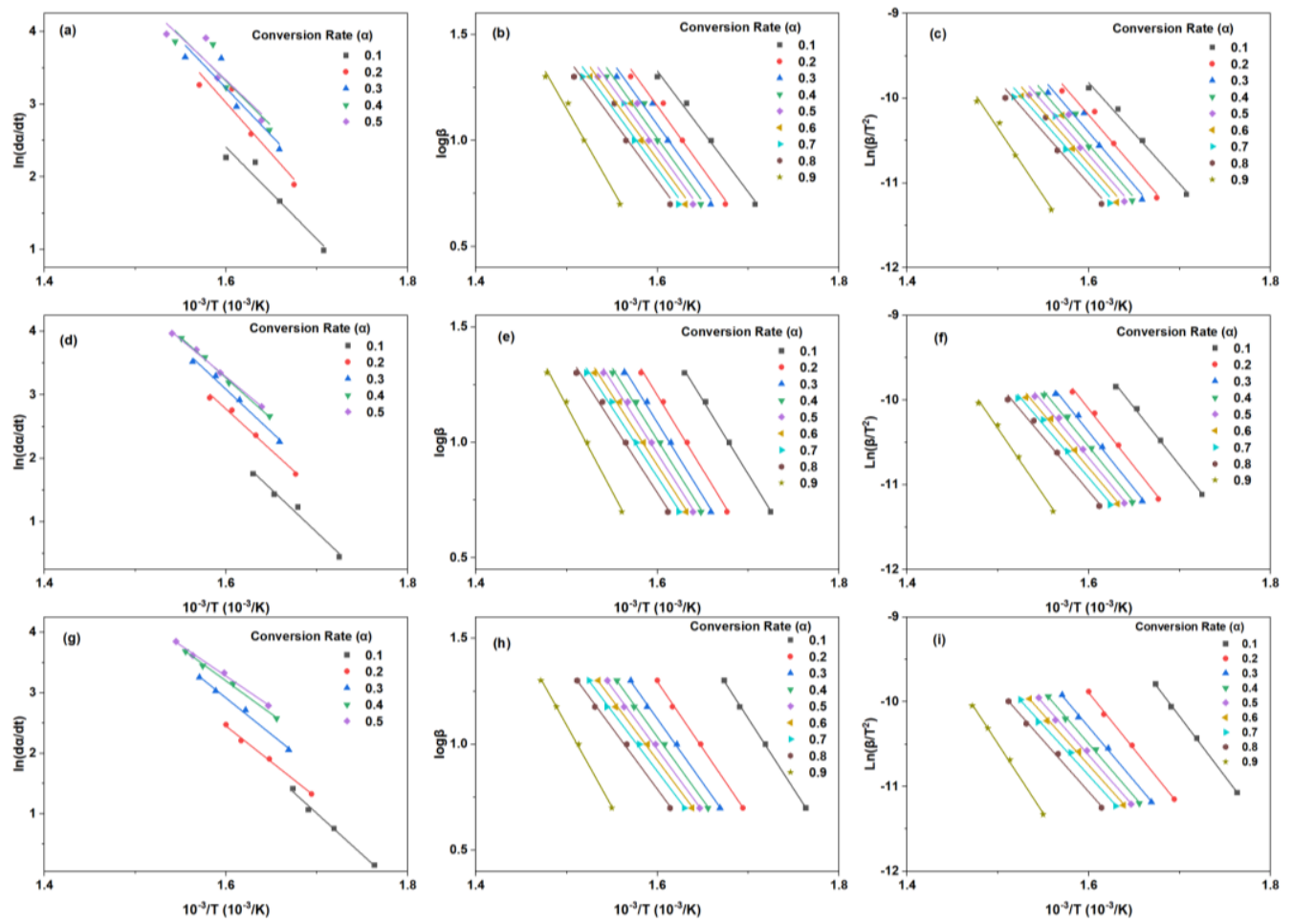

Figure 6. Iso-conversion plot for PW, PW9S1, and PW8S2 using FD method (a, d, g), FWO method (b, e, h), and CR method (c, f, i).

Table 4 and Figure 7 show that the values of the AAE of PW, PW9S1, and PW8S2 by using the slopes of the FD, FWO, and CR according to different conversion rates. For PW filament, the mean AAE value obtained from FD method was $108.3 \mathrm{~kJ} / \mathrm{mol}$, which was slightly higher than $106.9 \mathrm{~kJ} / \mathrm{mol}$ (the FWO method) and $102.0 \mathrm{~kJ} / \mathrm{mol}$ (the CR method). For PW9S1 sample, the mean AAE value from FD method was $109.6 \mathrm{~kJ} / \mathrm{mol}$, which was smaller than $113.4 \mathrm{~kJ} / \mathrm{mol}$ (the FWO method) and higher than $108.9 \mathrm{~kJ} / \mathrm{mol}$ (the CR method). Last, for PM8S2 sample, the AAE values calculated from FD, FWO, and CR methods were $97.4 \mathrm{~kJ} / \mathrm{mol}, 109.1 \mathrm{~kJ} / \mathrm{mol}$, and $104.5 \mathrm{~kJ} / \mathrm{mol}$, respectively. As shown in Figure 7, the AAE values were observed to be mainly in a 'band' shape between $97 \mathrm{~kJ} / \mathrm{mol}$ and $114 \mathrm{~kJ} / \mathrm{mol}$. 
Table 4. AAE values of the three model-free FD, FWO, and CR methods with conversion rate between 0.1 and 0.8 .

\begin{tabular}{|c|c|c|c|c|c|c|c|}
\hline Sample & $\begin{array}{c}\text { Conversion } \\
\text { rate }\end{array}$ & $\begin{array}{c}\text { FD } \\
\text { Ea } \\
(\mathrm{KJ} / \mathrm{mol})\end{array}$ & $\mathbf{R}^{2}$ & $\begin{array}{c}\text { FWO } \\
\text { Ea } \\
(\mathrm{KJ} / \mathrm{mol})\end{array}$ & $\mathbf{R}^{2}$ & $\begin{array}{c}\text { CR } \\
\text { Ea } \\
(\mathrm{KJ} / \mathrm{mol})\end{array}$ & $\mathbf{R}^{2}$ \\
\hline \multirow{9}{*}{ PW } & 0.1 & 104.8 & 0.9093 & 103.7 & 0.9849 & 99.0 & 0.9815 \\
\hline & 0.2 & 116.9 & 0.8567 & 107.9 & 0.9661 & 103.3 & 0.9588 \\
\hline & 0.3 & 108.8 & 0.7865 & 108.7 & 0.9469 & 104.0 & 0.9358 \\
\hline & 0.4 & 102.8 & 0.7787 & 108.4 & 0.9338 & 103.6 & 0.9200 \\
\hline & 0.5 & & & 107.5 & 0.9235 & 102.6 & 0.9076 \\
\hline & 0.6 & & & 106.9 & 0.9136 & 101.9 & 0.8956 \\
\hline & 0.7 & & & 106.2 & 0.9093 & 101.1 & 0.8901 \\
\hline & 0.8 & & & 106.3 & 0.9187 & 101.2 & 0.9012 \\
\hline & mean & 108.3 & 0.8328 & 106.9 & 0.9371 & 102.0 & 0.9238 \\
\hline \multirow{8}{*}{ PW9S1 } & 0.1 & 112.4 & 0.9706 & 116.8 & 0.9977 & 112.9 & 0.9972 \\
\hline & 0.2 & 108.3 & 0.9842 & 117.2 & 0.9945 & 113.0 & 0.9933 \\
\hline & 0.3 & 111.4 & 0.9844 & 115.9 & 0.9934 & 111.6 & 0.9919 \\
\hline & 0.4 & 106.3 & 0.9959 & 114.2 & 0.9932 & 109.7 & 0.9916 \\
\hline & 0.5 & & & 112.5 & 0.9926 & 107.8 & 0.9909 \\
\hline & 0.6 & & & 110.8 & 0.9917 & 106.0 & 0.9898 \\
\hline & 0.7 & & & 109.6 & 0.9911 & 104.7 & 0.9890 \\
\hline & 0.8 & & & 110.8 & 0.9897 & 105.9 & 0.9874 \\
\hline \multirow{10}{*}{ PW8S2 } & mean & 109.6 & 0.9838 & 113.4 & 0.9930 & 108.9 & 0.9914 \\
\hline & 0.1 & 113.1 & 0.9877 & 121.0 & 0.9993 & 117.6 & 0.9992 \\
\hline & 0.2 & 98.6 & 0.9948 & 114.8 & 0.9982 & 110.6 & 0.9978 \\
\hline & 0.3 & 100.0 & 0.9916 & 110.0 & 0.9979 & 105.4 & 0.9974 \\
\hline & 0.4 & 90.6 & 0.9944 & 108.1 & 0.9978 & 103.3 & 0.9973 \\
\hline & 0.5 & 84.7 & 0.9943 & 106.2 & 0.9974 & 101.3 & 0.9968 \\
\hline & 0.6 & & & 104.4 & 0.9975 & 99.4 & 0.9969 \\
\hline & 0.7 & & & 103.2 & 0.9971 & 97.9 & 0.9964 \\
\hline & 0.8 & & & 105.7 & 0.9967 & 100.5 & 0.9958 \\
\hline & mean & 97.4 & 0.9926 & 109.1 & 0.9977 & 104.5 & 0.9972 \\
\hline
\end{tabular}

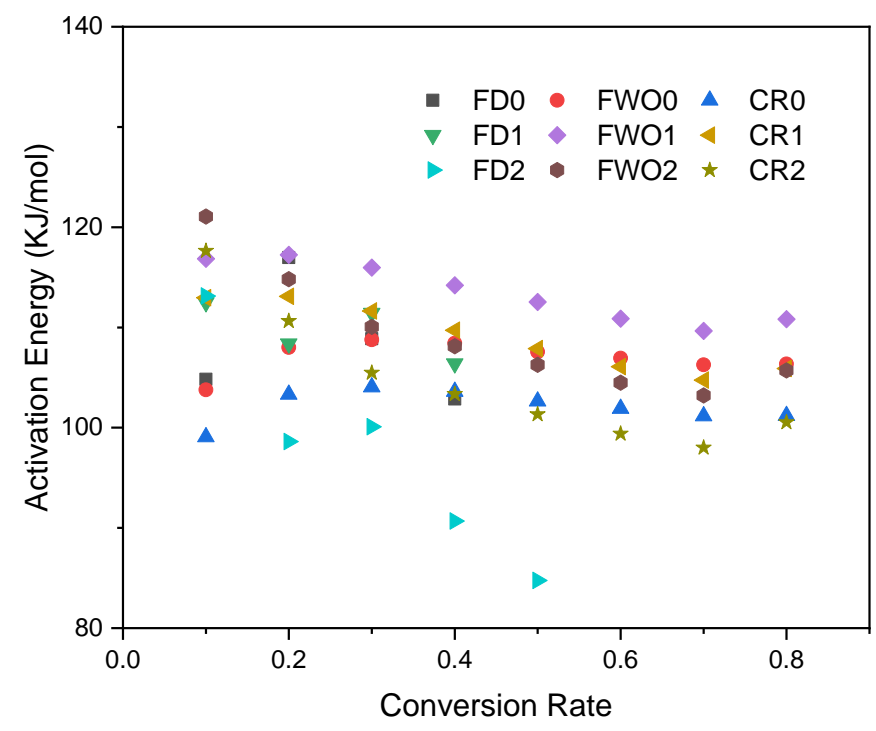

Figure 7. A comparison of AAE values at different conversion rates for PW (0), PW9S1(1), and PW8S2(2) from FD, FWO, and CR models.

The AAE values for the three filaments were also calculated with the Kissinger (KS) method, (Figure 8). The AAE values of PW, PW9S1, and PW8S2 were $99.9 \mathrm{~kJ} / \mathrm{mol}, 102.8 \mathrm{~kJ} / \mathrm{mol}$, 
and $97.6 \mathrm{~kJ} / \mathrm{mol}$, respectively. Comparing with the AAE values from other three methods as listed in Table 4, the AAE values were relatively smaller except the AAE value of $97.4 \mathrm{~kJ} / \mathrm{mol}$ with the FD method for the PW8S2 filament. The difference was thought to be due to different model formats in deriving the AAE values [32]. The AAE value information is helpful in understanding thermal decomposition with different analytical methods [32].

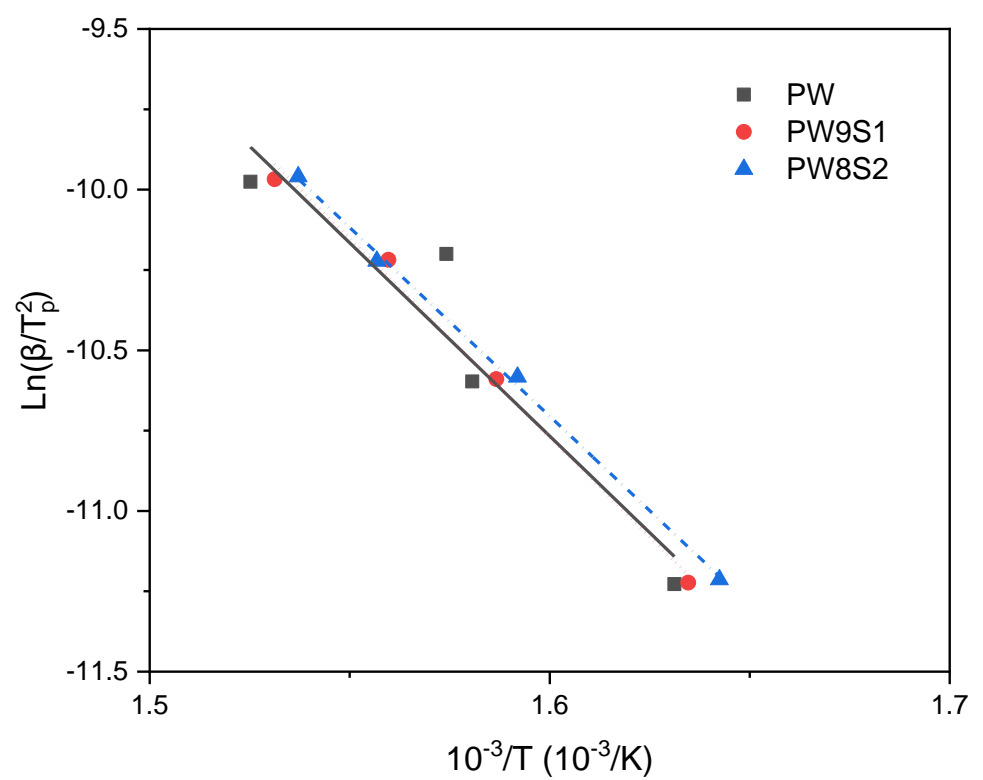

Figure 8. Relationship of $\ln \beta / \mathrm{T}_{\mathrm{p}}{ }^{2}$ versus $1 / \mathrm{T}_{\mathrm{p}}$ from the Kissinger model for PW, PW9S1, and PW8S2 samples.

\section{Conclusions}

This study demonstrates morphology, chemical structure and thermal decomposition properties of wood-filled PLA/TPS blend filaments for 3D printing. Morphology analysis shows presence of both wood filler and TPS particles in the system. There was little bonding between filler (wood) and PLA matrix in the original commercial filament, indicating an uncompatibilized wood-PLA blend. FTIR results indicated that filament with higher TPS content showed more surface chemical structural change. The onset thermal degradation temperatures of the three filaments were $272.4^{\circ} \mathrm{C}, 230.5^{\circ} \mathrm{C}, 155.1^{\circ} \mathrm{C}$, respectively, showing a gradual decrease with the increased starch ratio in the filament. The overall thermal degradation degree became smaller and the temperature $\left(\mathrm{T}_{\mathrm{s}}-\mathrm{T}_{\mathrm{o}}\right)$ interval became larger with increased starch content. The AAE values for all filaments varied from $97 \mathrm{~kJ} / \mathrm{mol}$ to $114 \mathrm{~kJ} / \mathrm{mol}$, depending on material composition (i.e., starch content) and method of calculation. The Kissinger (KS) method led to smaller AAE values, compared with data from the FD, FWO, and $\mathrm{CR}$ methods. The kinetic temperatures and $\mathrm{AAE}$ values obtained from various methods can help improve understanding of thermal decomposition behavior of more biodegradable PLAstarch based filaments for 3D printing.

Author Contributions: YS and QW designed the study. YS and DL conducted the test. DL, JG, JY and XL helped to analyze data. YS, YW and QW wrote the initial manuscript. YS, JG, GX, DL and SL reviewed and revised manuscript. All authors read and approved the manuscript.

Funding: This study was supported by China Scholarship Council - Grant No. 201808410102, Henan Scientific and Technological Research Program - Grant No. 182102110027 (Zhengzhou, China), National Institute of Forest Science (Seoul, Korea) and the USDA NIFA McIntire Stennis project - Project No. 1000017 (Baton Rouge, LA, USA). 
Conflicts of Interest: The authors declare no conflict of interest.

\section{References}

1. Dong, Y.; Milentis, J.; Pramanik, A. Additive manufacturing of mechanical testing samples based on virgin poly (lactic acid)(PLA) and PLA/wood fibre composites. Advances in Manufacturing 2018, 6, 7182.

2. A third industrial revolution. The Economist Apr 21st 2012, 2012.

3. Schubert, C.; Van Langeveld, M.C.; Donoso, L.A. Innovations in 3D printing: a 3D overview from optics to organs. British Journal of Ophthalmology 2014, 98, 159-161.

4. Sin, L.T.; Rahmat, A.R.; Rahman, W.A.W.A. Polylactic Acid: PLA Biopolymer Technology and Applications; Elsevier Science: 2012; https://doi.org/10.1016/C2010-0-65966-9.

5. Cosate De Andrade, M.F.; Souza, P.M.S.; Cavalett, O.; Morales, A.R. Life Cycle Assessment of Poly(Lactic Acid) (PLA): Comparison Between Chemical Recycling, Mechanical Recycling and Composting. Journal of Polymers and the Environment 2016, 24, 372-384, doi:10.1007/s10924-016-0787-2.

6. Groot, W.J.; Borén, T. Life cycle assessment of the manufacture of lactide and PLA biopolymers from sugarcane in Thailand. The International Journal of Life Cycle Assessment 2010, 15, 970-984, doi:10.1007/s11367-010-0225-y.

7. Vink, E.T.H.; Davies, S. Life Cycle Inventory and Impact Assessment Data for 2014 Ingeo $^{\mathrm{TM}}$ Polylactide Production. Industrial Biotechnology 2015, 11, 167-180, doi:10.1089/ind.2015.0003.

8. Auras, R.A.; Lim, L.T.; Selke, S.E.M.; Tsuji, H. Poly(lactic acid): Synthesis, Structures, Properties, Processing, and Applications; Wiley: 2010; https://doi.org/10.1002/9780470649848.

9. Kutnar, A.; Muthu, S.S. Environmental impacts of traditional and innovative forest-based bioproducts; Springer: 2016.

10. Averous, L. Biodegradable multiphase systems based on plasticized starch: a review. Journal of Macromolecular Science, Part C: Polymer Reviews 2004, 44, 231-274.

11. Schwach, E.; Six, J.-L.; Avérous, L. Biodegradable Blends Based on Starch and Poly(Lactic Acid): Comparison of Different Strategies and Estimate of Compatibilization. Journal of Polymers and the Environment 2008, 16, 286-297, doi:10.1007/s10924-008-0107-6.

12. Wang, N.; Yu, J.; Ma, X. Preparation and characterization of thermoplastic starch/PLA blends by one-step reactive extrusion. Polymer International 2007, 56, 1440-1447.

13. Mihai, M.; Legros, N.; Alemdar, A. Formulation-properties versatility of wood fiber biocomposites based on polylactide and polylactide/thermoplastic starch blends. Polymer Engineering \& Science 2014, 54, 1325-1340.

14. Lu, D.; Xiao, C.; Xu, S. Starch-based completely biodegradable polymer materials. Express polymer letters 2009, 3, 366-375.

15. Schwach, E.; Averous, L. Starch-based biodegradable blends: morphology and interface properties. Polymer International 2004, 53, 2115-2124.

16. Jang, W.Y.; Shin, B.Y.; Lee, T.J.; Narayan, R. Thermal properties and morphology of biodegradable PLA/starch compatibilized blends. Journal of Industrial and Engineering Chemistry 2007, 13, 457-464.

17. Jacobsen, S.; Fritz, H.-G. Plasticizing polylactide-the effect of different plasticizers on the mechanical properties. Polymer Engineering \& Science 1999, 39, 1303-1310.

18. Park, J.W.; Im, S.S.; Kim, S.H.; Kim, Y.H. Biodegradable polymer blends of poly (L-lactic acid) and gelatinized starch. Polymer Engineering \& Science 2000, 40, 2539-2550.

19. Lv, S.; Zhang, Y.; Gu, J.; Tan, H. Biodegradation behavior and modelling of soil burial effect on degradation rate of PLA blended with starch and wood flour. Colloids and Surfaces B: Biointerfaces 2017, 159, 800-808.

20. Mao, L.; Imam, S.; Gordon, S.; Cinelli, P.; Chiellini, E. Extruded cornstarch-glycerol-polyvinyl alcohol blends: mechanical properties, morphology, and biodegradability. Journal of Polymers and the Environment 2000, 8, 205-211.

21. Lai, S.M.; Huang, C.K.; Shen, H.F. Preparation and properties of biodegradable poly(butylene succinate)/starch blends. 2005, 97, 257-264, doi:10.1002/app.21679.

22. Kim, S.H.; Chin, I.J.; Yoon, J.; Jung, J. Mechanical properties of biodegradable blends of poly (Llactic acid) and starch. Korea Polymer Journal 1998, 6, 422-427.

23. Ohkita, T.; Lee, S.H. Thermal degradation and biodegradability of poly (lactic acid)/corn starch biocomposites. Journal of applied polymer science 2006, 100, 3009-3017.

24. Acioli-Moura, R.; Sun, X.S. Thermal degradation and physical aging of poly(lactic acid) and its blends with starch. Polymer Engineering \& Science 2008, 48, 829-836, doi:10.1002/pen.21019. 
25. Liu, X.; Khor, S.; Petinakis, E.; Yu, L.; Simon, G.; Dean, K.; Bateman, S. Effects of hydrophilic fillers on the thermal degradation of poly (lactic acid). Thermochimica Acta 2010, 509, 147-151.

26. Chapple, S.; Anandjiwala, R.; Ray, S.S. Mechanical, thermal, and fire properties of polylactide/starch blend/clay composites. Journal of Thermal Analysis and Calorimetry 2013, 113, 703-712, doi:10.1007/s10973-012-2776-6.

27. Wokadala, O.C.; Emmambux, N.M.; Ray, S.S. Inducing PLA/starch compatibility through butyletherification of waxy and high amylose starch. Carbohydrate polymers 2014, 112, 216-224.

28. Lv, S.; Zhang, Y.; Gu, J.; Tan, H. Soil burial-induced chemical and thermal changes in starch/poly (lactic acid) composites. International journal of biological macromolecules 2018, 113, 338-344.

29. Zuo, Y.; Gu, J.; Cao, J.; Wei, S.; Tan, H.; Zhang, Y. Effect of starch/polylactic acid ratio on the interdependence of two-phase and the properties of composites. Journal of Wuhan University of Technology-Mater. Sci. Ed. 2015, 30, 1108-1114.

30. Petinakis, E.; Liu, X.; Yu, L.; Way, C.; Sangwan, P.; Dean, K.; Bateman, S.; Edward, G. Biodegradation and thermal decomposition of poly (lactic acid)-based materials reinforced by hydrophilic fillers. Polymer Degradation and Stability 2010, 95, 1704-1707.

31. Grønli, M.G.; Várhegyi, G.; Di Blasi, C. Thermogravimetric analysis and devolatilization kinetics of wood. Industrial \& Engineering Chemistry Research 2002, 41, 4201-4208.

32. Yao, F.; Wu, Q.; Lei, Y.; Guo, W.; Xu, Y. Thermal decomposition kinetics of natural fibers: activation energy with dynamic thermogravimetric analysis. Polymer Degradation and Stability 2008, 93, 90-98.

33. Li, W.; Wang, Z.; Wang, Y.; Xu, G.; Li, M.; Sun, X.; Vlosky, R.; Li, G.; Lv, Y.; Wu, Q. Comparison of Thermal Decomposition Behavior of Lignocellulosic Nanomaterials from Two Biomass Sources. Journal of Biobased Materials and Bioenergy 2018, 12, 441-448.

34. Brown, M.; Maciejewski, M.; Vyazovkin, S.; Nomen, R.; Sempere, J.; Burnham, A.a.; Opfermann, J.; Strey, R.; Anderson, H.; Kemmler, A. Computational aspects of kinetic analysis: part A: the ICTAC kinetics project-data, methods and results. Thermochimica Acta 2000, 355, 125-143.

35. Cai, J.; Liu, M.; Wang, L.; Yao, K.; Li, S.; Xiong, H. Isothermal crystallization kinetics of thermoplastic starch/poly (lactic acid) composites. Carbohydrate polymers 2011, 86, 941-947.

36. Wang, N.; Yu, J.; Chang, P.R.; Ma, X. Influence of formamide and water on the properties of thermoplastic starch/poly (lactic acid) blends. Carbohydrate polymers 2008, 71, 109-118.

37. Oza, S.; Ning, H.; Ferguson, I.; Lu, N. Effect of surface treatment on thermal stability of the hempPLA composites: correlation of activation energy with thermal degradation. Composites Part B: Engineering 2014, 67, 227-232.

38. Huda, M.; Drzal, L.; Misra, M.; Mohanty, A. Wood-fiber-reinforced poly (lactic acid) composites: evaluation of the physicomechanical and morphological properties. Journal of Applied Polymer Science 2006, 102, 4856-4869.

39. Zhang, C.; Man, C.; Wang, W.; Jiang, L.; Dan, Y. Degradation of poly (L-lactide) films under ultraviolet irradiation and water bath. Polymer-Plastics Technology and Engineering 2011, 50, 810-817.

40. Doganay, D.; Coskun, S.; Kaynak, C.; Unalan, H.E. Electrical, mechanical and thermal properties of aligned silver nanowire/polylactide nanocomposite films. Composites Part B: Engineering 2016, 99, 288-296.

41. Lv, S.; Liu, X.; Gu, J.; Jiang, Y.; Tan, H.; Zhang, Y. Effect of glycerol introduced into PLA based composites on the UV weathering behavior. Construction and Building Materials 2017, 144, 525-531.

42. Olewnik-Kruszkowska, E.; Koter, I.; Skopińska-Wiśniewska, J.; Richert, J. Degradation of polylactide composites under UV irradiation at $254 \mathrm{~nm}$. Journal of Photochemistry and Photobiology A: Chemistry 2015, 311, 144-153.

43. Lv, S.; Gu, J.; Tan, H.; Zhang, Y. The morphology, rheological, and mechanical properties of wood flour/starch/poly (lactic acid) blends. Journal of Applied Polymer Science 2017, 134. 